\title{
AVALIAÇÃO SENSORIAL DE FEIJÃO PRETO SUBMETIDO À RADIAÇÃO DE COBALTO-60
}

\author{
Neila Camargo de MOURA ; Solange Guidolin CANNIATTI-BRAZACA**; \\ Marta Helena Fillet SPOTO ; Valter ARTHUR
}

\section{RESUMO}

O objetivo dessa pesquisa foi o de avaliar os aspectos sensoriais do feijão preto submetido à radiação gama do "Co. O estudo envolveu oito provadores, na faixa etária de 17 a 23 anos, selecionados e treinados para Análise Descritiva Quantitativa. Os provadores verificaram alterações quanto à aparência, aroma, sabor e textura em feijão preto irradiado com doses $2,4,6,8$ e 10kGy e feijão preto não irradiado. Para a análise estatística dos resultados obtidos foram aplicados, o teste F, ANOVA e o teste de Tukey (5\%) com o uso de computadores e do programa específico para análise sensorial Compusense Five e SAS. As amostras irradiadas apresentaram diminuição do sabor amargo, cor acentuada e brilhante e a não irradiada textura seca. Deste modo, a irradiação como método de conservação pode ser utilizada para o feijão preto com as doses avaliadas no presente estudo.

Palavras-chave: irradiação de alimentos; Phaseolus vulgaris; conservação de grãos; sensorial; leguminosas.

\section{SUMMARY}

SENSORY EVALUATION OF BLACK BEANS SUBMITTED TO GAMMA RADIATION FROM COBALT-60. The objective of this research was to evaluate the sensory aspects of black beans submitted to gamma radiation from ${ }^{\circ} \mathrm{Co}$. The study involved eight panelists, between 17 to 23 years old, who were selected and trained for the descriptive analysis of appearance, aroma, flavor and texture. The panelists analyzed alterations of appearance, aroma, flavor and texture of non-irradiated and irradiated black beans with doses 2, 4, 6, 8 and 10kGy. The results were analyzed by test F, ANOVA and the Tukey test (5\%), with the use of computers and the sensory analysis software Compusense Five and SAS. The results showed that irradiated samples decreased the bitter flavor, accentuated color and brightness and samples non-irradiated dry texture. The radiation treatment is a good method for conservation of black beans in doses evaluated in this study.

Keywords: food irradiation; Phaseolus vulgaris; grain conservation; sensory; legumes.

\section{1 - INTRODUÇÃO}

O feijão é conhecido como fonte de proteina, sendo que seu valor biológico é mais baixo quando comparado com proteínas de origem animal. Tem especial importância no Brasil, não somente pelo país ser o maior produtor e consumidor mundial, mas também por ser o feijão um dos principais alimentos protéicos do povo brasileiro $[7,11]$.

Além de ser uma boa fonte de proteínas, o feijão, possui também carboidratos complexos e fibras, baixo teor de lipídios e sódio, e não contém colesterol. A principal reserva de carboidratos está na forma de amido, com pequenas quantidades de mono e dissacarídeos, como por exemplo, a sacarose. Outros carboidratos presentes são fibras, substâncias pécticas, arabinogalactanas e xiloglicanas [7].

Dada a sua composição, o feijão proporciona vários beneficios à saúde, sendo indicado na prevenção e no tra-

Recebido para publicação em 03/05/2004. Aceito para publicação em 04/05/2005(001334).

Departamento de Agroindústria, Alimentos e Nutrição da Escola Superior "Luiz de Queiroz", Universidade de São Paulo.

Seção de Entomologia e Irradiação de Alimentos, Centro de Energia Nuclear na Agricultura, Universidade de São Paulo. End.: Av. Pádua Dias, n. 11. Caixa Postal: 9. CEP: 13418-900, Piracicaba-SP. E-mail: sgcbraza@esalq.usp.br

A quem a correspondência deve ser enviada. tamento de várias doenças como: distúrbios cardiacos, diabetes mellitus, obesidade e câncer. Os feijões são alimentos que preenchem as principais recomendações dietéticas para a boa saúde: aumento do consumo de fibras, amido e outros carboidratos complexos e diminuição no consumo de lipídios e sódio. Assim, as principais instituições internacionais de apoio e promoção à saúde indicam a ingestão diária de uma ou mais porções de feijão $[5,12]$.

Além dos benefícios para o bom funcionamento do organismo, o feijão preto apresenta em sua composição compostos fenólicos, entre os quais os taninos, que recebem grande destaque. Estes são responsáveis pelo sabor adstringente e podem interagir com as proteínas do feijão, decrescendo a sua digestibilidade e utilização [3].

Ocorrem perdas desses grãos a cada colheita devido, entre outros fatores, ao ataque de insetos e roedores, além de alterações físico-químicas, por transformações estruturais de seus componentes, resultando em feijões que apresentam elevada resistência à cocção, com modificações das propriedades organolépticas e nutricionais $[8,15]$.

Para combater essas perdas, o processo de irradiação dos feijões é uma alternativa mais atrativa e saudável, quando comparada aos tratamentos químicos, por exemplo, brometo de metila. Este processo, tendo o propósito de preservar e desinfestar grãos, surge como prática promissora, utilizada para estender a vida útil e redu- 
zir as perdas das safras durante a armazenagem do produto. Os custos estimados dos benefícios da irradiação comercial, como tratamento, mostram ser competitivos em comparação aos tratamentos físicos e térmicos [9, 15].

A irradiação é um método de pasteurização a frio utilizado para controlar doenças de origem alimentar, causadas por microrganismos patogênicos, parasitas, especialmente em alimentos que são consumidos crus ou parcialmente processados, além de apresentar característica única de poder ser aplicada em alimentos congelados [4].

No Brasil, a Resolução RDC no 21 de 26/01/2001 aprovou o "Regulamento Técnico para a Irradiação de Alimentos" que permite a irradiação de qualquer alimento, com a condição de que a dose máxima absorvida seja inferior àquela que comprometa as propriedades funcionais e/ou os atributos sensoriais do alimento e que a dose minima absorvida seja suficiente para alcançar o objetivo pretendido [1].

A irradiação de alimentos com doses de 2-7kGy, pode reduzir significativamente os microrganismos patogênicos, como Salmonella spp, Staphylococcus aureus, e Escherichia. coli O157:H7 [6].

O objetivo do trabalho foi analisar as propriedades sensoriais: aparência, textura, aroma e sabor do feijão preto irradiado com doses de 2, 4, 6, 8 e 10kGy e compará-las ao feijão preto não irradiado.

\section{2 - MATERIAL E MÉTODOS}

Os grãos foram adquiridos no comércio local da cidade de Piracicaba-SP, Brasil, posteriormente separados em cinco lotes os quais receberam diferentes tratamentos. O feijão preto foi irradiado em irradiador de Cobalto60, tipo Gammacell da Nordion com atividade de 1.519,06 Ci (CENA/USP). As doses utilizadas foram 0 , 2, 4, 6, 8 e 10kGy. Após a irradiação, as amostras foram deixadas em maceração por oito horas antes de serem submetidas à cocção, após esse período foram lavadas e cozidas em panela de pressão comum durante dez minutos e preparadas sem a adição de cloreto de sódio, para não mascarar o sabor original do alimento.

Para a formação da equipe sensorial, os participantes foram submetidos a três fases: seleção, treinamento para Análise Descritiva Qualitativa (ADQ) e a análise sensorial propriamente dita.

A seleção de provadores e as demais fases foram realizadas no Laboratório de Análise Sensorial, do Departamento de Agroindústria, Alimentos e Nutrição da Escola Superior de Agricultura "Luiz de Queiroz" (ESALQ/USP). A seleção foi feita através do teste de reconhecimento de gostos básicos: doce ( $2,0 \%$ sacarose), ácido ( $0,07 \%$ ácido cítrico), salgado ( $0,2 \%$ cloreto de sódio) e amargo (0,07\% cafeína). Essas soluções foram servidas aos provadores em copos plásticos descartáveis dispostos aleatoriamente em bandejas. $\mathrm{O}$ teste foi realizado em sala com temperatura controlada, estando os provadores individualmente isolados em cabines apropriadas. Foi pedido aos mesmos que não engolissem as amostras e lavassem a boca com água entre as provas. Foram selecionados os provadores com $100 \%$ de acerto, os fumantes e os com idade acima de 50 anos foram excluídos, dando preferência aos que possuíam disponibilidade de tempo para participar dos testes. Com base nesses critérios, a equipe sensorial foi composta por oito provadores sendo três homens e cinco mulheres, na faixa etária de 17 a 23 anos.

$\mathrm{Na}$ fase de treinamento da Análise Descritiva Qualitativa (ADQ), desenvolveu-se a terminologia descritiva através da identificação dos atributos sensoriais da aparência, aroma, sabor e textura. Para que os provadores pudessem marcar a intensidade de cada atributo foi utilizada uma escala estruturada de 0 a $10 \mathrm{~cm}$, ancorada nas extremidades com os termos "pouco e muito" e "claro e escuro" [14]. Foram oferecidas aos membros da equipe amostras de feijão preto cozido com dois tratamentos: sem irradiação e irradiado com 10kGy .

Os provadores descreveram em uma ficha suas impressões em relação à aparência, à textura, ao aroma e ao sabor, a partir desse teste foi coletada uma lista de atributos referentes às características das amostras. Nessa fase, realizou-se um encontro semanal com os provadores, durante um mês, totalizando quatro encontros. Depois, em um único encontro posterior, sob a supervisão do coordenador, o grupo discutiu os termos que seriam utilizados na ficha de avaliação final. Desta forma, alguns termos foram substituídos, tornando-se possivel agrupá-los, formando um conjunto para as amostras de feijão preto com quatro atributos para a aparência: "cor", "brilho", "característico" e "tamanho"; dois para aroma "característico" e "estranho"; quatro para sabor "característico", "estranho", "azedo" e "amargo" e três para textura "firme", "granulosa" e "seca".

A fase da análise sensorial compreendeu três testes e em cada um foram avaliadas amostras do feijão preto submetido a duas doses distintas de irradiação. As doses utilizadas foram: 0 e $2 \mathrm{kGy}$ no primeiro teste; 6 e $8 \mathrm{kGy}$ no segundo teste e 4 e $10 \mathrm{kGy}$ no terceiro teste. Cada provador recebeu seis amostras de feijão preto por dia de teste, sendo duas doses com três repetições para cada dosagem de irradiação.

Os resultados obtidos foram submetidos à análise de variância com aplicação do teste F. Quando o valor de F foi significativo em nível de $5 \%$, a análise estatística teve continuidade através do teste de Tukey, também foi aplicado o teste ANOVA para os atributos [10].

Os dados obtidos foram analisados com o auxílio do programa específico para análise sensorial Compusense Five release [2] e SAS [13].

\section{3 - RESULTADOS E DISCUSSÃO}

Para o feijão preto irradiado foram realizados testes 
de Análise Descritiva Quantitativa obtendo-se os resultados apresentados nas Tabelas 1, 2, 3 e 4 e Figura 1.

$\mathrm{Na}$ avaliação da aparência, todas as amostras foram consideradas "características" e não ocorreu alteração de "cor" entre o feijão preto não irradiado e os irradiados em diferentes doses. A amostra irradiada com a dose de $2 \mathrm{kGy}$ foi a que obteve maior nota para o atributo "cor" e para o atributo "característico". O mesmo não ocorreu com o atributo "brilho", pois as amostras irradiadas apresentaram diferença estatística (5\%) a partir da dose de $4 \mathrm{kGy}$, sendo mais brilhantes. A amostra irradiada com 2kGy diferiu em relação a que recebeu a dose de 6kGy quanto ao atributo "tamanho", isto pode ser explicado por algum problema que possa ter ocorrido em termos de hidratação do grão. A amostra que recebeu a dose de $6 \mathrm{kGy}$ foi a que apresentou a maior média para aparência

TABELA 1 - Médias da aparência de feijão preto irradiado

\begin{tabular}{|c|c|c|c|c|c|c|c|}
\hline \multicolumn{8}{|c|}{ Doses (kGy) } \\
\hline Atributos & 0 & 2 & 4 & 6 & 8 & 10 & $\begin{array}{l}\text { Desvio Padrão } \\
\text { Médio }\end{array}$ \\
\hline Cor & $4,25^{1} \pm 1,9^{\text {abc2 }}$ & $5,13 \pm 1,8^{a}$ & $3,83 \pm 1,3^{b c}$ & $4,75 \pm 1,9^{\mathrm{abc}}$ & $3,63 \pm 1,9^{c}$ & $4,83 \pm 1,5^{\mathrm{ab}}$ & 1,3 \\
\hline Característico & $4,50 \pm 2,5^{\mathrm{a}}$ & $5,67 \pm 2,4^{a}$ & $4,96 \pm 2,1^{a}$ & $5,21 \pm 2,1^{a}$ & $4,96 \pm 2,0^{a}$ & $4,96 \pm 1,5^{\mathrm{a}}$ & 1,5 \\
\hline Brilho & $3,33 \pm 1,9^{b}$ & $3,13 \pm 1,5^{b}$ & $4,75 \pm 1,5^{\mathrm{a}}$ & $5,83 \pm 2,0^{a}$ & $5,46 \pm 2,4^{a}$ & $5,33 \pm 1,1^{a}$ & 1,7 \\
\hline Tamanho & $4,83 \pm 1,9^{a b}$ & $5,58 \pm 1,1^{a}$ & $4,71 \pm 1,4^{a b}$ & $4,63 \pm 1,1^{b}$ & $4,79 \pm 1,3^{a b}$ & $4,88 \pm 1,1^{a b}$ & 1,1 \\
\hline
\end{tabular}

${ }^{1}$ Médias de três repetições \pm Desvio Padrão ANOVA

${ }^{2}$ Médias com letras diferentes nas linhas diferem significativamente no nível $\mathrm{p}<0,05 \%$.

TABELA 2 - Médias do aroma de feijão preto irradiado

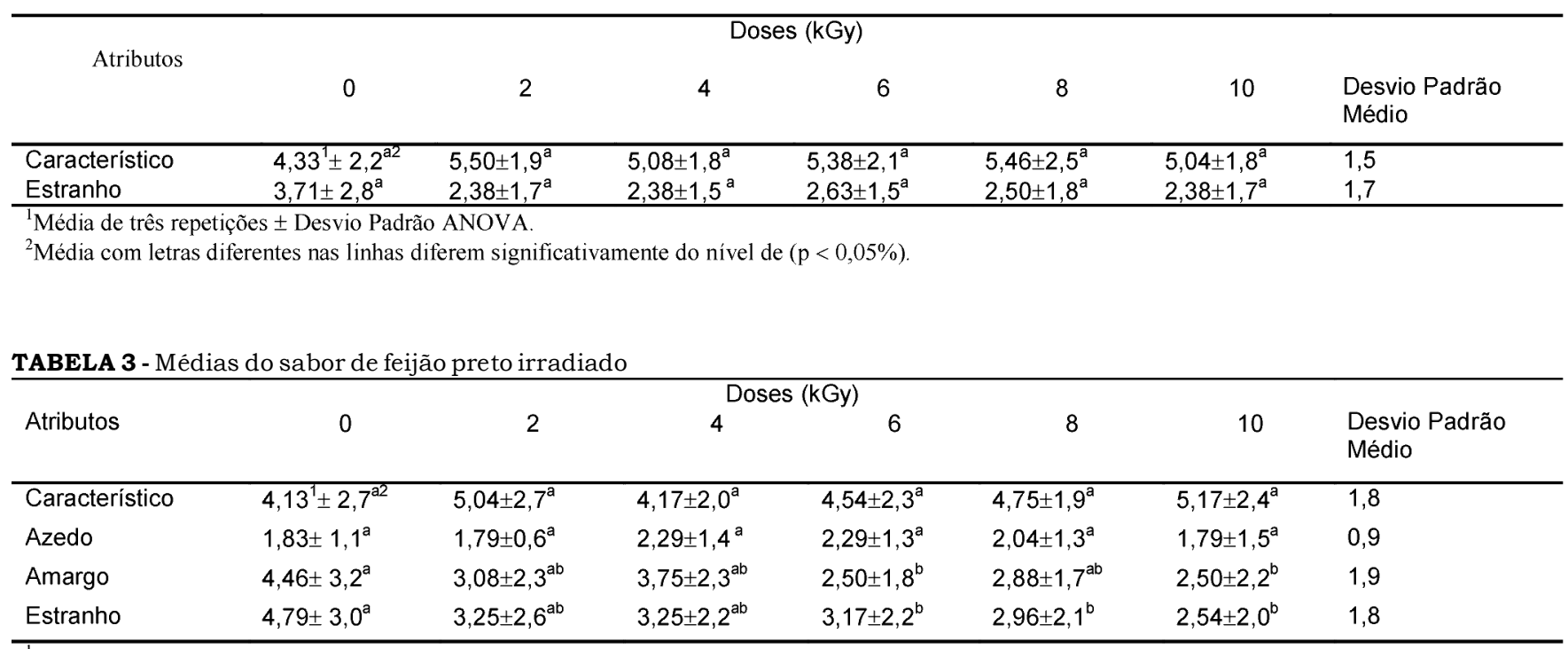

${ }^{1}$ Média de três repetições \pm Desvio Padrão ANOVA.

${ }^{2}$ Média com letras diferentes nas linhas diferem significativamente do nível de $(\mathrm{p}<0,05 \%)$.

TABELA 4 - Médias de textura de feijão preto irradiado

\begin{tabular}{|c|c|c|c|c|c|c|c|}
\hline \multicolumn{8}{|c|}{ Doses (kGy) } \\
\hline Firme & $5,67^{1} \pm 2,7^{\mathrm{a} 2}$ & $5,46 \pm 2,5^{\mathrm{a}}$ & $4,29 \pm 1,6^{\mathrm{a}}$ & $4,63 \pm 2,1^{\mathrm{a}}$ & $5,13 \pm 1,6^{a}$ & $4,71 \pm 1,5^{\mathrm{a}}$ & 1,7 \\
\hline Seco & $5,08 \pm 2,5^{\mathrm{a}}$ & $4,13 \pm 2,6^{\mathrm{ab}}$ & $3,08 \pm 1,8^{b}$ & $2,88 \pm 2,0^{b}$ & $3,29 \pm 2,0^{b}$ & $3,08 \pm 2,2^{b}$ & 1,6 \\
\hline Granulosa & $3,71 \pm 2,1^{a}$ & $2,46 \pm 2,2^{\mathrm{a}}$ & $3,38 \pm 2,3^{\mathrm{a}}$ & $2,92 \pm 1,9^{a}$ & $2,92 \pm 1,9^{a}$ & $3,67 \pm 2,4^{a}$ & 1,7 \\
\hline
\end{tabular}

\footnotetext{
${ }^{1}$ Média de três repetições \pm Desvio Padrão ANOVA.

${ }^{2}$ Média com letras diferentes nas linhas diferem significativamente do nível de $(p<0,05 \%)$
} 


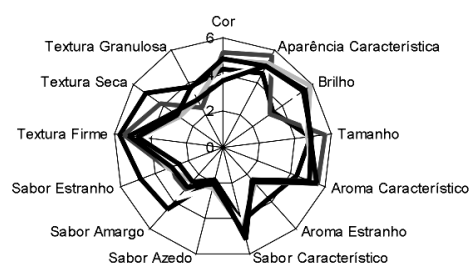

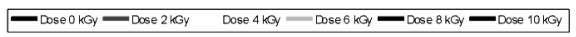

FIGURA 1 - Gráfico das propriedades sensoriais do feijão preto submetido a diferentes doses de radiação

seguida da amostra que recebeu a dose de 10kGy. O atributo "característico" foi o que apresentou as maiores notas entre os atributos de aparência (Tabela 1 e Figura 1).

O aroma "característico" não se alterou com a irradiação, os diferentes tratamentos aplicados não apresentaram diferença estatística $(5 \%)$ e obteve média maior que "estranho". Entretanto, a amostra não irradiada apresentou os maiores valores para o parâmetro sensorial "estranho" diferindo da amostra irradiada com 10kGy (Tabela 2 e Figura 1). O sabor "estranho" também foi apresentado pela amostra não irradiada diferindo das irradiadas com doses superiores a 6kGy. Este sabor "estranho" pode estar relacionado com o sabor "amargo" que foi identificado nas amostras não irradiadas e com menores doses de radiação. A amostra não irradiada apresentou maiores notas para o atributo "amargo" e "estranho". Isto pode ser explicado pelo processo de irradiação destruir parcialmente substâncias fenólicas diminuindo a percepção de amargor e sabor estranho dos grãos. Todas as amostras foram consideradas com sabor "característico". O atributo "azedo" foi igual para todas as amostras (Tabela 3 e Figura 1).

As médias obtidas para a amostra não irradiada foram maiores que as amostras irradiadas quanto ao aroma, sabor e textura. O parâmetro "característico" apresentou as maiores médias para aroma e sabor.

Referente a textura, as amostras irradiadas foram consideradas com notas significativamente inferiores à amostra não irradiada para o atributo "seco", porém outros atributos avaliados não apresentaram alterações. $\mathrm{O}$ atributo "firme" apresentou a maior média (Tabela $4 e$ Figura 1).

\section{4 - CONCLUSÕES}

A irradiação no feijão preto obteve resultados expressivos e satisfatórios, especialmente na amostra irradiada com a dose de 6kGy que apresentou melhor aparência. A amostra irradiada com $2 \mathrm{kGy}$ apresentou melhor aroma, além disso todas as am ostras irradiadas apresentaram diminuição do sabor "amargo" e "estranho". Assim, a irradiação com Cobalto-60 mostrou ser um processo que interfere de forma positiva nas características sensoriais do feijão preto.

\section{5 - REFERÊNCIAS BIBLIOGRÁFICAS}

[1] BRASIL. Resolução RDC n.21, de 26 de jan. 2001. Diário Oficial da União, Brasília, n.20-E, 29 de janeiro de 2001. Seção 1, p.35. Agência Nacional de Vigilância Sanitária aprova o Regulamento Técnico para Irradiação de Alimentos.

[2] COMPUSENSE Five. Software for sensory analysis. Compusense five, release 3.0(software). Compusense five Manual version 3.0/3.6 64p. Compusense Inc. Guelph, Ontário, Canadá 1998. 1CD-ROM.

[3] DUARTE, M.S.L. Digestibilidade in vivo e in vitro de proteinas de feijão preto. Viçosa, 1999, 63p. Dissertação (Mestrado) Universidade Federal de Viçosa.

[4] FARKAS, J. Irradiation as a method for decontamination food. A review. Intl. J. Food Microbiol., v. 44, p.189204, 1998.

[5] GEIL, P.B., ANDERSON, J.W. Nutrition and health implications of dry beans: a review. J.Am. Col.Nutr.,v.13, n.6, p.549-558, 1994.

[6] GELLI, D.S; JAKABI, M; SAKATA, H; FERNANDES, S.A; TRAVECCHIO, A .T; PERESI, J.T.M; FREITAS, ${ }^{\mathrm{a}} \mathrm{M}$; ESPER, M.R.N.R; PISANI, B; SIMÕES, M; PACHECO, M.A.S.R., FONSECA, Y.S.K., KAKU, M., MARTINS, A.M.B., RIBEIRO, E.G.A ., CASTRO, M.T.F., FAUSTINO, J.S., TANAKA, A .Y., GOMES, S.M.M. Salmonelas isoladas de alimentos no período de 1985-1996 no estado de São Paulo, Brasil. In: CONGRESSO LATINOAMERICANO DE MICROBIOLOGIA DE ALIMENTOS (COMBHAL), 5, Águas de Lindóia, 1998. Livro de Resumos. São Paulo: SBM, 1998. P.105, res.Q.101.

[7] GONÇALVES, J.S.; SOUZA, S.A.M. Gangorra de preços: a produção e o abastecimento de feijão na safra 1997/98 no Estado de São Paulo. Informações Econômicas, v. 28, n.6, p.60-65, 1998.

[8] MANCINI-FILHO, J. Efeitos das radiações gama sobre algumas caracteristicas físico-quimicas e nutricionais de feijões (Phaseolus vulgaris L.) armazenados. São Paulo. 1990. 100p. Tese (Livre Docência) - Faculdade de Ciências Farmacêuticas, Universidade de São Paulo.

[9] NASCIMENTO, L.M. Efeito da radiação gama ( Co) nas propriedades físico-quimicas e sensoriais de feijões envelhecidos (Phaseolus vulgaris). São Paulo,1992. 135p. Tese (Doutorado) - Faculdade de Ciências Farmacêuticas, Universidade São Paulo.

[10] Pimentel GOMES, F. Curso de estatística experimental. 10 ed. São Paulo: Nobel, 1982, 468p.

[11] RIOS, A.O. Avaliação da época de colheita e do armazenamento no escurecimento e digestibilidade de três cultivares de feijão (Phaseolus vulgaris, L.). Lavras, 2000. 59p. (Dissertação) - Escola Superior de Agricultura de Lavras.

[12] SATHE, S.K., DESPhandE, S.S., SALUnKE, D.K. Dry beans of Phaseolus: a review I. Chemical composition proteins. Critical Review Food Science Nutrition, v.20, n.5, p. 31-39, 1984.

[13] STATISTICAL ANALYSIS SYSTEM INSTITUTE. Sas/Qc software: usage and reference. 2.ed. Cary, 1996. 2v. 
[14] STONE, H.; SIDEL, J.L. Sensory evaluation practices. New York, Academic Press, 1985, 311p.

[15] VILlaViCENCIO, A.L.C.H. Avaliação dos efeitos da radiação ionizante de "Co em propriedades físicas, químicas e nutricionais dos feijões Phaseolus vulgaris L. e Vigna unguiculata (L.) Walp. São Paulo, 1998. 138p. Tese (Doutorado) - Faculdade de Ciências Farmacêuticas, Universidade de São Paulo. 